\title{
Avaliação dos parâmetros do processo de usinagem química com $\mathrm{NaOH}$ em tubos quadrados de alumínio
}

\author{
Evaluation of the parameters of the \\ chemical machining process with $\mathrm{NaOH}$ in \\ square aluminum tubes
}

Cassiano Rodrigues Moura ${ }^{1}$

Arthur Gabriel Scaburi²

${ }^{1}$ Instituto Federal de Santa Catarina (IFSC). Mestre em Ciências e Engenharia de Materiais (UDESC). Graduado em Engenharia de Produção e Sistemas (UDESC). Pós-graduado em Logística. Pós-graduado em Engenharia de produção.

Professor do Instituto Federal de Santa Catarina (IFSC),

alocado no Campus Jaraguá do Sul - Rau / SC, Brasil.

cassiano.moura@ifsc.edu.br

${ }^{2}$ Instituto Federal de Santa Catarina (IFSC). Especialista em

Engenharia Produção. Graduado em Tecnologia em Fabricação Mecânica (IFSC). Profissional certificado Six Sigma. Atualmente é projetista mecânico na WEG Equipamentos

Elétricos S.A. Tem experiência na área de Engenharia Mecânica e Elétrica, com ênfase em projeto de Motores Elétricos. Jaraguá do Sul - Rau / SC, Brasil. agscaburi@gmail.com
Resumo

O processo de usinagem química consiste na remoção de material de áreas específicas, através da corrosão do substrato por uma forte reação química através de uma substância reagente, em condições controladas. É um dos mais importantes processos não convencionais de usinagem, com o qual é possível realizar a usinagem de geometrias complexas, com dimensões reduzidas ou ainda reduzir o peso de determinadas peças. Diante disso, o objetivo deste trabalho é a avaliação do processo de usinagem química com $\mathrm{NaOH}$ em tubo quadrado de alumínio através da variação de seus parâmetros. Para isso, o alumínio foi usinado com a variação dos seguintes parâmetros: concentração do reagente, temperatura da reação e tempo de reação. A caracterização dos corpos de prova foi realizada através da microscopia óptica e análise da taxa de remoção, onde podem-se observar quais as melhores condições para se realizar o processo de usinagem química.

Palavras-chave: Usinagem Química; Alumínio; Hidróxido de Sódio.

\section{Abstract}

The process of chemical etching consists in the removal of material from specific areas, through corrosion of the substrate by a strong chemical reaction through a reagent substance, in controlled conditions. It is one of the most important non-conventional machining processes, with which it is possible to etch complex geometries, with reduced dimensions or even to reduce the weight of certain parts. Therefore, the objective of this work is to evaluate the process of chemical etching with $\mathrm{NaOH}$ in square aluminum tubes through the variation of its parameters. For this, the aluminum was etched with the variation of the following parameters: reagent concentration, reaction temperature and reaction time. The characterization of the specimens was performed by optical microscopy and analysis of the removal rate, from which one can observe the best conditions to perform the chemical etching process.

Keywords: Chemical etching; Aluminum; Sodium hydroxide. 


\section{Introdução}

A área de processos não convencionais de usinagem é foco de constante estudo e investimento no que tange às suas aplicações, especialmente porque se caracterizam majoritariamente como mais baratos e usuais se comparados aos processos convencionais de usinagem. Um desses processos é a usinagem química, que corrói materiais utilizando ácidos ou bases em condições controladas. A técnica tem sido utilizada pelo ser humano desde tempos remotos, cujo objetivo era produzir efeitos artísticos em metais, onde um reagente era utilizado para corroer a superfície do metal, criando baixo relevo.

A usinagem química dos metais é empregada na fabricação ou beneficiamento de peças para a indústria mecânica, aeroespacial e eletrônica. Dentre os principais metais usinados temos o alumínio, o cobre e o aço, sendo que a usinagem do alumínio é empregada largamente.

De acordo com Huang et al. (2015), esta larga utilização ocorre porque o processo possibilita a redução do peso das peças, bem como a obtenção de perfis específicos de rugosidade, como é o caso das aplicações superhidrofóbicas, ou a remoção de material que caracteriza uma usinagem propriamente dita. De acordo com Çakir et al. (2008), alguns estudos têm sido realizados para determinar qual o melhor reagente para se usinar o alumínio. Os resultados destes estudos indicam o hidróxido de sódio $(\mathrm{NaOH})$ e cloreto de ferro III (FeCl3) como os mais eficientes. Determinados perfis de alumínio, como o tubo quadrado fino, só podem ser usinados com baixas forças de usinagem. Essas forças causam deformação plástica devido à baixa resiliência do material, uma vez que as propriedades mecânicas do alumínio associadas a uma seção fina fragilizam a estrutura.

Para solucionar este problema, utilizam-se processos não convencionais como corte a laser, corte a plasma ou eletroerosão. O problema destes processos é o alto custo agregado, pois há a necessidade de maquinário e equipamentos específicos para o processo. Diante desta exposição bibliográfica, percebe-se uma lacuna de pesquisa para aprofundamento deste tema que é de fundamental importância para as indústrias mecânicas, a fim de expor novos estudos que contribuam com novas alternativas para a fabricação destas peças com alto índice de complexidade. Assim, o processo da usinagem química pode oferecer para a indústria metalmecânica soluções eficazes de maneira viável e acessível.

Diante do exposto, o objetivo deste trabalho é a avaliação da variação de parâmetros do processo da usinagem química com $\mathrm{NaOH}$ em tubo quadrado de alumínio, com o propósito de determinar quais são as melhores condições para se obter qualidades de trabalho alinhadas à taxa de remoção de material. O método empregado na pesquisa é experimental, uma vez que as variáveis são controláveis dentro do procedimento metodológico adotado com o intuito do pesquisador analisar seus efeitos sobre o objeto em estudo (Lakatos; Marconi, 2011).

\section{Revisão da literatura \\ 2.1 Descrição do processo de usinagem química}

Para a fabricação de superfícies de liga de alumínio superhidrofóbicas, este tipo de processo de produção já é amplamente utilizado pela indústria e se mostrou eficaz para obter superfícies ásperas. Alguns destes estudos 
fizeram corrosão do substrato de ligas de alumínio através de HCl - Ácido clorídrico (Saleema et al. 2011; Ruan et al. 2012; Liao et al. 2014; Bernagozzi et al. 2014).

De acordo com Walker e Tarn (1991), a usinagem química (chemical etching, chemical milling, chemical machining) é um dos processos não convencionais de usinagem, cuja característica principal é a utilização de um reagente ácido ou alcalino, que corrói materiais em condições controladas. É um processo que remove material de substratos metálicos, de polímeros ou de compósitos através da corrosão, utilizando parâmetros preestabelecidos. A energia é proveniente da própria reação química, podendo ser potencializada por elementos externos. De acordo com Fiorotto (2014), durante o processo de reação o laboratório ou local onde for realizado o processo, deve ser mantido ventilado e arejado, uma vez que é gerado gás hidrogênio $\left(\mathrm{H}_{2}\right)$, que é muito volátil e inflamável, podendo ser prejudicial à saúde se não for tomada às devidas precauções. Conforme Fiorotto (2014), os resíduos gerados devem ser tratados ou recondicionados antes do seu descarte. O descarte de resíduos no Brasil é regido pela norma ABNT NBR 10004 Classificação de Resíduos Sólidos.

A reação química e consequente corrosão irão ocorrer apenas nas áreas do substrato que terão contato direto com a solução agressiva ácida ou alcalina. Então, é necessário delimitar quais áreas sofrerão corrosão e quais áreas permanecerão intactas. Isso porque uma vez iniciada a reação, a corrosão atingirá porções cada vez mais profundas do substrato. Para isso é necessária a utilização de uma máscara, que é um revestimento utilizado no processo para realizar esta delimitação.

Conforme se pode observar na Figura 1, a máscara deverá aderir à superfície do substrato e permanecer assim durante todo o procedimento, e só deverá ser removida quando a reação química for interrompida (Nayak et al. 2005). Para cessar a reação, é necessário remover o substrato da solução reagente e neutralizar seus resíduos.

Figura 1 - Etapas da reação a) Início da reação b) Reação em profundidade

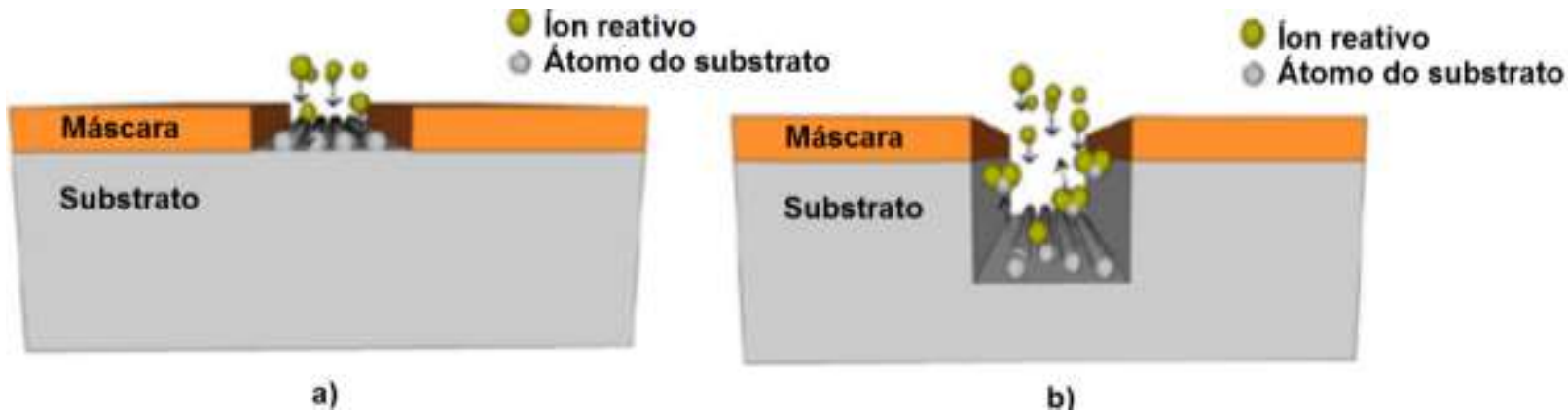

Fonte: Adaptado de Nayak et al. (2005).

Como em qualquer outro processo de usinagem, existem parâmetros que podem ser variados para aumentar a taxa de remoção de material, melhorar a precisão dimensional do perfil geométrico usinado ou obter diferentes perfis de rugosidade. Os parâmetros que podem ser variados são: 
- Tipo e concentração do reagente;

- Temperatura da reação;

- Tempo da reação;

— Elemento potencializador aplicado (tensão, radiação, plasma, movimento).

A seleção do reagente adequado para cada tipo de material caracteriza qual será o tipo de usinagem química (etch type). Segundo Walker e Tarn (1991), ao todo existem 248 tipos de reagentes para os diversos materiais, que são ácidos ou bases com diferentes concentrações. O estado destas substâncias também pode variar, geralmente são soluções líquidas, mas podem ser aplicadas no estado sólido ou gasoso.

A intensidade da reação na superfície do material pode ser desde fraca, alterando apenas o perfil de rugosidade até forte, removendo uma maior quantidade de material e caracterizando uma usinagem em profundidade. Segundo Tarasova (1968), se essa usinagem remover uma pequena espessura do material criando rebaixos na peça, então ela é classificada como fresamento químico (chemical milling). Já se a usinagem realizar uma remoção profunda de material, por vezes cortando sua seção e criando porções vazadas, é classificada como usinagem química em profundidade (deep etch). É importante que a reação seja bem controlada, para que se possa obter um resultado satisfatório.

As normas que padronizam esse processo são a ASTM E407 - Prática Padrão para Microusinagem Química de Metais e Ligas (Standard Practice for Microetching Metals and Alloys), a ASTM E340 Método de Teste Padrão para Macrousinagem Química de Metais e Ligas (Standard Test Method for Macroetching Metals and Alloys) e a ASTM D1193 Especificação para Solução Reagente (Specification for Reagent Water).

\subsubsection{Reagentes}

Conforme Chandler (2008), os reagentes utilizados para usinar alumínio podem ter natureza alcalina (bases) como o hidróxido de sódio $(\mathrm{NaOH})$, ácida como o ácido clorídrico $(\mathrm{HCl})$ ou cloreto de ferro $\mathrm{III}\left(\mathrm{FeCl}_{3}\right)$. São mais de 100 catalogados. Os diversos estudos sobre a eficiência dos reagentes para usinar este material concluíram que aqueles de natureza alcalina como as bases, apresentam melhores resultados.

O FeCl 3 foi um reagente bastante estudado e apresenta uma série de características que tornam muito comuns a sua utilização, entretanto existem algumas limitações técnicas por ser de natureza ácida e além de possuir custo elevado. Por outro lado, uma vantagem do cloreto de ferro seria a possibilidade de recondicionar a solução após o uso.

É importante, portanto, comparar as vantagens e desvantagens de se usinar o alumínio com uma solução ácida ou alcalina.

O hidróxido de sódio $(\mathrm{NaOH})$ ou soda cáustica, como é popularmente conhecido, é tratado como reagente universal para processos de usinagem química do alumínio, uma vez que sua reação é fácil de controlar, possui natureza alcalina e custo reduzido. Por exemplo, $1 \mathrm{~kg}$ de hidróxido de sódio em escamas pode ser utilizado para usinar centenas de peças, pois cada diluição em solução líquida consumirá apenas alguns gramas do material. 
A ilustração da reação da solução alcalina com o substrato alumínio dá-se conforme mostra a Figura 2, onde de acordo com Torng (2009), durante o processo de usinagem química a água dissocia o hidróxido de sódio que ioniza a solução com $\mathrm{OH}^{-}$.

Quando o alumínio entra em contato com esta base e a reação é iniciada, quem ataca o alumínio é a água ionizada. Diferente do que acontece na reação que utiliza cloreto de ferro, se a solução de hidróxido de sódio ficar fraca, porém receber mais água, então a reação continuará acontecendo.

Figura 2 - Solução alcalina reagindo com o substrato alumínio

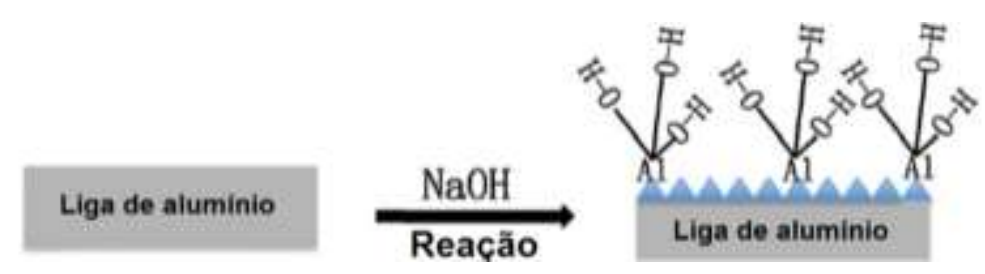

Fonte: Adaptado de Huang et al. (2015).

De acordo com Çakir et al. (2008), esta reação deve ser configurada em banho-maria, conforme mostra a Figura 3, para que a água auxilie na homogeneização da temperatura e dissipe o calor da reação exotérmica.

Figura 3 - Configuração da reação em banho-maria

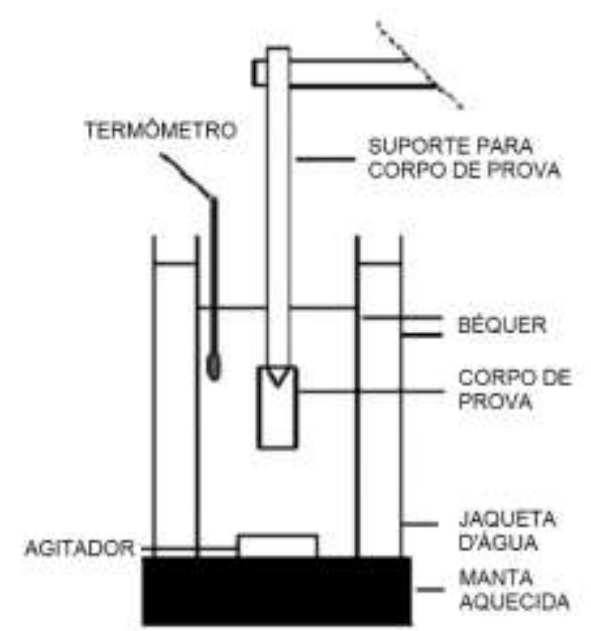

Fonte: Çakir et al. (2008). 


\subsubsection{Máscaras}

As máscaras utilizadas no processo têm a função de delimitar quais áreas das peças serão usinadas. Dessa maneira, uma máscara deve aderir à peça, protegendo as partes que não deverão ser atacadas pelo reagente. De fato, o reagente pode não corroer a peça apenas no sentido vertical. Dependendo dos parâmetros de usinagem selecionados e da reatividade química do substrato a ser usinado, é possível que o reagente também corroa o substrato por baixo da máscara. A característica que define o tipo de usinagem química em relação à direção da corrosão é chamada de isotropia da usinagem.

De acordo com Nayak et al. (2005) a usinagem pode ser completamente anisotrópica, parcialmente anisotrópica ou isotrópica, conforme mostra a Figura 4. O objetivo é que o tipo de usinagem seja completamente anisotrópica. Desta maneira, é possível garantir que as dimensões nominais do perfil geométrico (dimensões de projeto) terão pouca variação após o processo de usinagem química.

Figura 4 - Isotropia da usinagem química a) totalmente anisotrópico b) parcialmente anisotrópico c) isotrópico

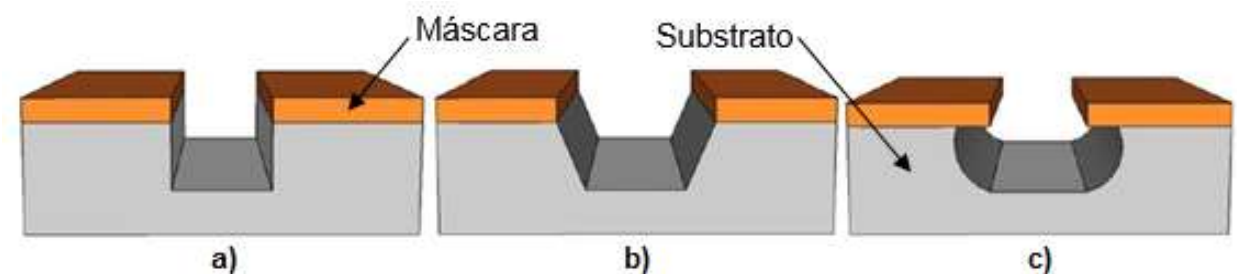

Fonte: Adaptado de Nayak et al. (2005).

Conforme Allen (1986), o projeto da máscara deve considerar variáveis como o reagente que será utilizado na reação química; o material do substrato e a espessura deste substrato. Atualmente, a maioria dos projetos dimensionais das máscaras são realizados utilizando software CAD, onde o detalhamento 2D da máscara gera um desenho dimensional na escala desejada, podendo ser impresso e utilizado como gabarito para aplicação da máscara.

A natureza do reagente determina qual tipo de material deve ser utilizado na fabricação da máscara. Este material deve ser resistente ao reagente, mas não deve causar uma reação de neutralização para não enfraquecer o reagente. Seu material pode ser um polímero como plástico ou borracha, ou pode ser um líquido polimerizante como tintas, vernizes, resinas ou acrílicos.

Estes podem ser ainda fotossensíveis, que polimerizam mediante a presença de luz com comprimento de onda e intensidade adequados. Este tipo de máscara é ideal para peças com dimensões muito reduzidas, como processadores de computador e outros componentes da eletrônica que possuem dimensões nanométricas.

Segundo Furtado (2009), determinadas tintas possuem propriedades anticorrosivas, podendo ser utilizadas em ambientes agressivos, como em uma reação química. Uma máscara para usinagem química pode 
ser confeccionada deste tipo de material. A vantagem de se utilizar uma pintura como máscara, é que assim como acontece com os demais líquidos polimerizantes, ela irá secar e aderir à superfície do substrato sem a necessidade da utilização de uma cola. No caso das máscaras rígidas, como as de plástico ou de borracha, deve-se colar a máscara na peça. Então uma série de outras variáveis devem ser consideradas, como a natureza química da cola e o desempenho quando em alta temperatura proveniente da reação.

\section{Metodologia}

A metodologia de pesquisa aplicada neste trabalho caracteriza-se por meio de pesquisa tecnológica através de uma aplicação prática em laboratório a fim de compreender as variáveis do processo. As etapas do procedimento experimental são apresentadas na Figura 5, onde pode-se observar que primeiramente foi necessário preparar os corpos que prova, para serem utilizados no procedimento prático e na sua caracterização.

Posteriormente, foi realizado o Procedimento prático de laboratório, onde foi desenvolvida a usinagem química propriamente dita, nesta etapa foram utilizados 12 corpos de prova, estes foram usinados quimicamente e posteriormente neutralizados.

Na sequência, foi realizada a caracterização dos corpos de prova, onde se podem avaliar as características de cada concentração utilizada. Nesta etapa foi analisada através de microscopia óptica a fim de verificar as condições de cada superfície usinada. Em seguida, foi avaliada a taxa de remoção de material e profundidade de usinagem, relacionando com os parâmetros de tempo, temperatura da reação e concentração do reagente.

Figura 5 - Etapas de do procedimento experimental

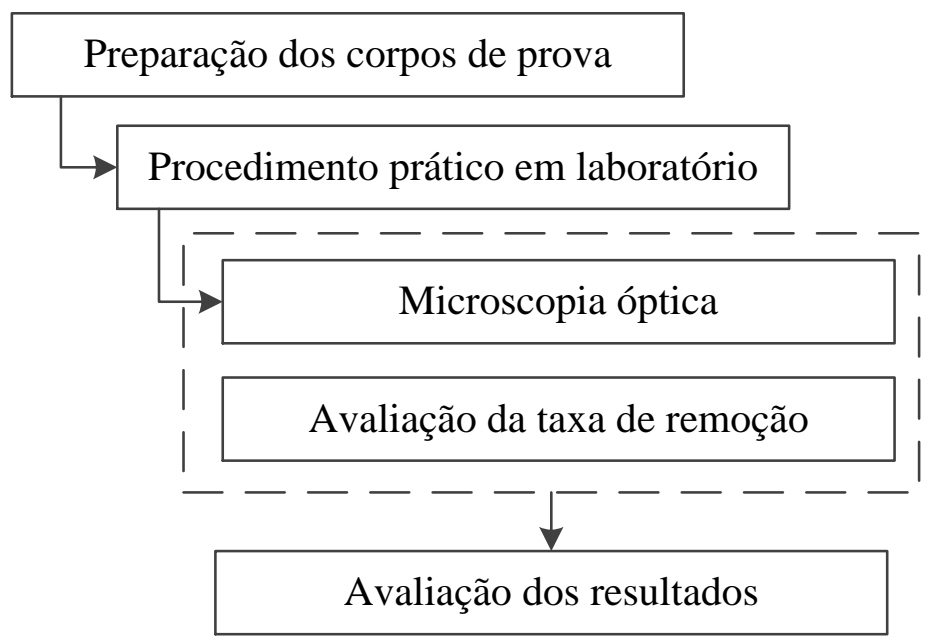

Fonte: Elaborado pelo próprio autor. 


\section{Resultados e discussões}

\subsection{Preparação dos corpos de prova}

Para a preparação dos corpos de prova foi utilizada como matéria-prima o tubo de alumínio quadrado TQ-023 da série 1050, da marca Alcoa, com comprimento de 6000mm, lado de 25,4mm. A espessura nominal é de $1 \mathrm{~mm}$, porém a espessura medida foi de $0,95 \mathrm{~mm}$. O tubo foi cortado em 12 partes com 50mm de comprimento cada, conforme mostra a Figura 6.

Figura 6 - Corpos de prova (a) peças cortadas (b) medidas nominais

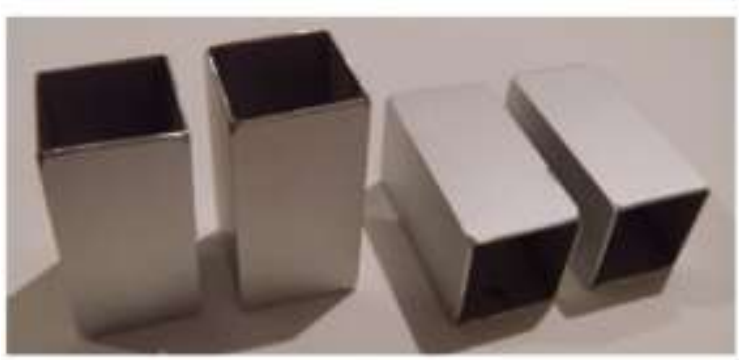

a)

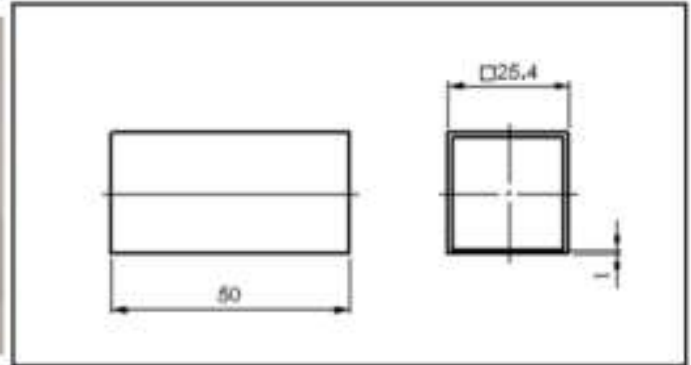

b)

Fonte: Elaborado pelo próprio autor.

Após cortados, estes tiveram as rebarbas removidas com auxílio de uma lima e, posteriormente, foram limpos. Para a limpeza, foram utilizadas soluções líquidas de acetona e nital (mistura de ácido nítrico com etanol, fórmula $\mathrm{HNO}_{3}+\mathrm{C}_{2} \mathrm{H}_{6} \mathrm{O}$ ) com $2 \%$ de concentração em volume.

Foram desenvolvidos gabaritos de papel com duas formas (cruz e círculo), suas dimensões podem ser vistas na Figura 7, bem como sua posição no corpo de prova.

Posteriormente estes gabaritos foram colados nos corpos de prova. Durante a colagem foi garantida a ausência de bolhas de ar sob os gabaritos, pois estas poderiam interferir na precisão geométrica das formas.

Figura 7 - Desenhos dimensionais (a) gabaritos (b) posição dos gabaritos no corpo de prova

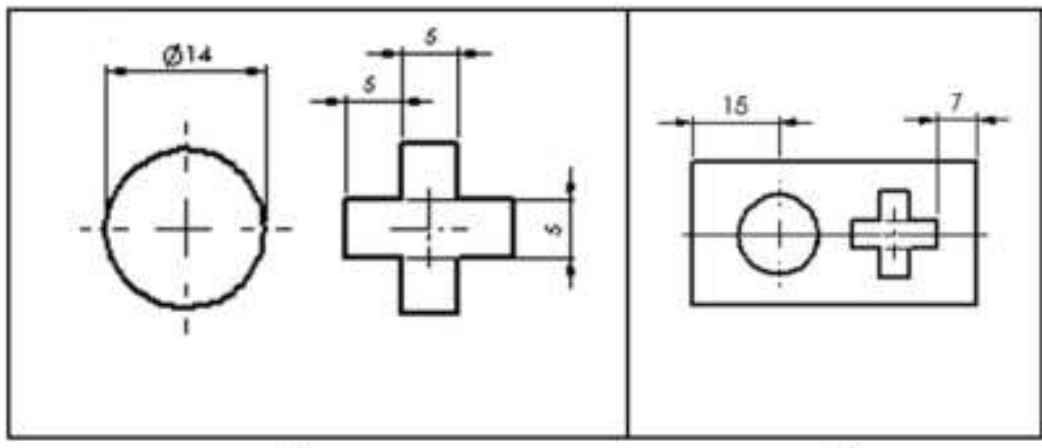

a)

Fonte: Elaborado pelo próprio autor. 


\subsection{Aplicação da máscara}

O tipo de máscara aplicada foi uma pintura, utilizando a tinta epóxi específica para este fim. Esta é composta por uma base (componente A) e um catalisador (componente B), dispostos em recipientes distintos. Utilizando a pistola para pintura spray, toda a extensão do corpo de prova foi pintada, inclusive a parte interna. Foram aplicadas 3 demãos, com intervalos de $2 \mathrm{~h}$ entre cada demão. Este tempo é o tempo de secagem e cura indicado pelo fabricante da tinta, que tem a característica de ser de secagem rápida (à base de nitrocelulose). Permaneceram sem pintura apenas as porções cobertas pelos gabaritos. É importante salientar que houve respingos de tinta sobre os gabaritos.

Após $2 \mathrm{~h}$ da terceira demão, os gabaritos foram removidos dos corpos de prova utilizando uma pinça. Esta etapa foi realizada com cautela para não danificar a máscara durante a remoção. Os resíduos da colagem do gabarito foram limpos com acetona. Os corpos de prova sem os gabaritos ficaram com áreas do substrato expostas, conforme mostra a Figura 8.

Figura 8 - Corpos de prova após a aplicação da máscara (sem os gabaritos)

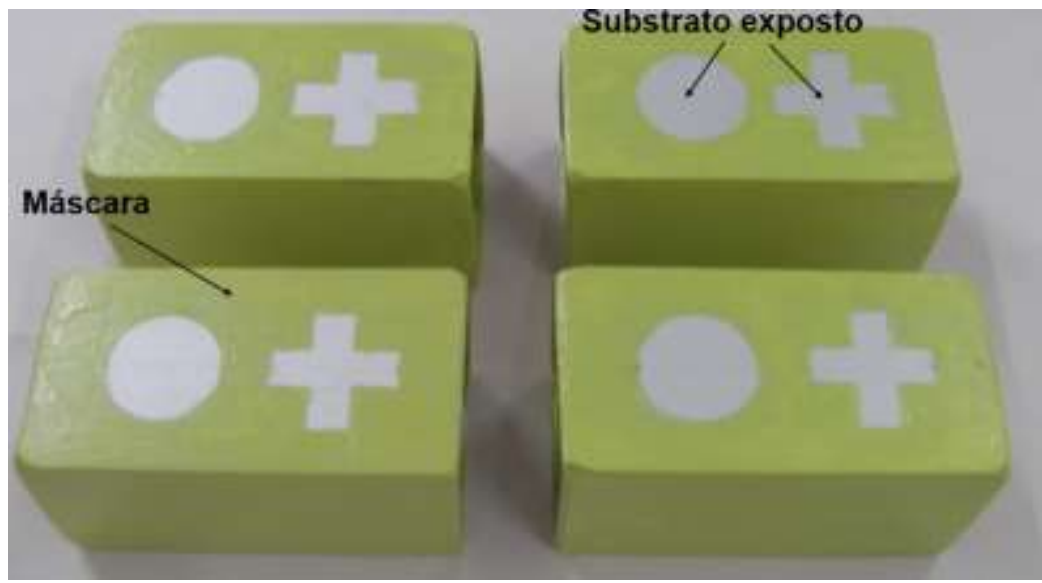

Fonte: Elaborado pelo próprio autor

\subsection{Usinagem química}

As etapas do procedimento prático em laboratório foram estipuladas conforme descreve a Figura 9, com os objetivos de realizar a usinagem química em todos os corpos de prova bem como descartar corretamente os resíduos gerados. 
Figura 9 - Procedimento prático em laboratório

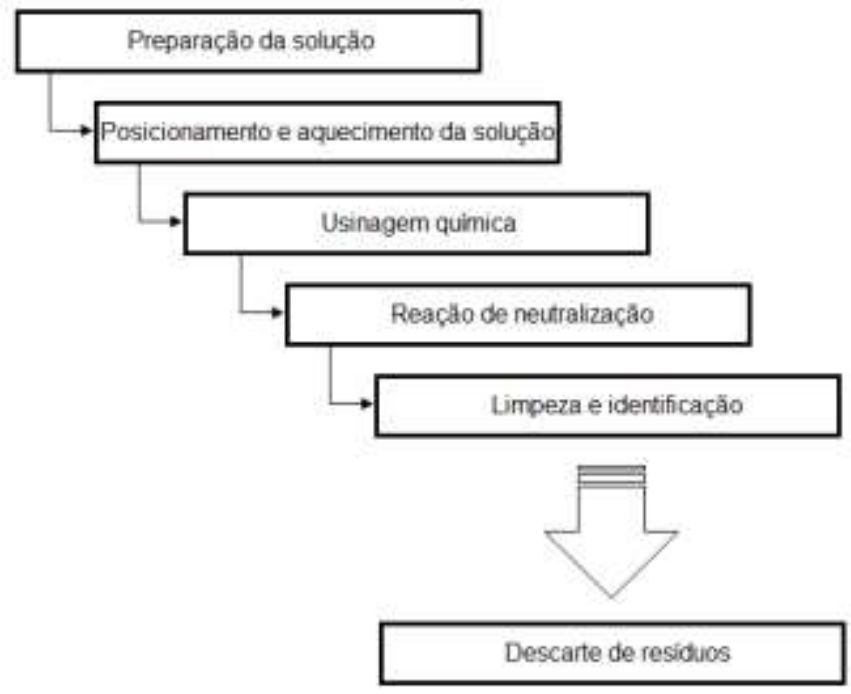

Fonte: Elaborado pelo próprio autor.

Durante o desenvolvimento do procedimento prático em laboratório, foram variados os seguintes parâmetros:

— Concentração do reagente $(1,5 ; 1,75 ; 2 ; 2,5 ; 4$ e 6 molar);

- Temperatura $\left(25 ; 60\right.$ e $\left.90^{\circ} \mathrm{C}\right)$

- Tempo (1 e 2h).

O procedimento prático em laboratório foi organizado de modo que, os doze corpos de prova foram divididos em três grupos, cada grupo sendo usinado uma vez e com parâmetros distintos. Os parâmetros foram variados para gerar resultados diferentes para o estudo de uma configuração mais satisfatória, sendo que esta variação foi baseada em dados da literatura referenciada neste trabalho. A Tabela 1 apresenta a configuração de cada grupo. Também é apresentada a variação de cada parâmetro utilizado.

Tabela 1 - Parâmetros de usinagem

\begin{tabular}{|c|c|c|c|c|}
\hline Identificação & Grupo & Concentraçāo (molar $\mathrm{NaOH}$ ) & Temperatura $\left({ }^{\circ} \mathrm{C}\right)$ & Tempo (h) \\
\hline Corpo de prova 1 & \multirow{3}{*}{01} & 2,5 & \multirow[t]{3}{*}{ 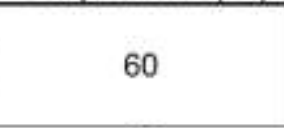 } & \multirow{3}{*}{1} \\
\hline Corpo de prova 2 & & 4 & & \\
\hline Corpo de prova 3 & & 6 & & \\
\hline Corpo de prova 4 & \multirow{3}{*}{02} & \multirow{3}{*}{1,5} & 25 & \multirow{9}{*}{2} \\
\hline Corpo de prova 5 & & & 60 & \\
\hline Corpo de prova 6 & & & 90 & \\
\hline Corpo de prova 7 & \multirow{3}{*}{03} & \multirow{3}{*}{1,75} & 25 & \\
\hline Corpo de prova 8 & & & 60 & \\
\hline Corpo de prova 9 & & & 90 & \\
\hline Corpo de prova 10 & \multirow{3}{*}{04} & \multirow{3}{*}{2} & 25 & \\
\hline Corpo de prova 11 & & & 60 & \\
\hline Corpo de prova 12 & & & 90 & \\
\hline
\end{tabular}

Fonte: Elaborado pelo próprio autor. 
Devido ao fenômeno da passivação, onde uma camada de óxido de alumínio é formada na superfície do substrato, foi necessário decapar as porções de alumínio expostas antes de dar início à usinagem química. Esta camada de óxido é bastante dura e resistente, de modo que iria interferir na reação entre o metal e o reagente.

Esta decapagem foi realizada molhando-se as superfícies em questão com ácido sulfúrico (H2SO4) na concentração de 9 molar. O ácido reagiu com a superfície durante 1 minuto.

O próximo passo foi inserir os três corpos de prova, cada um dentro de um béquer diferente sobre uma manta de aquecimento para iniciar a usinagem química. A Figura 10 apresenta a configuração dos equipamentos de laboratório durante este procedimento.

Figura 10 - Processo de usinagem química

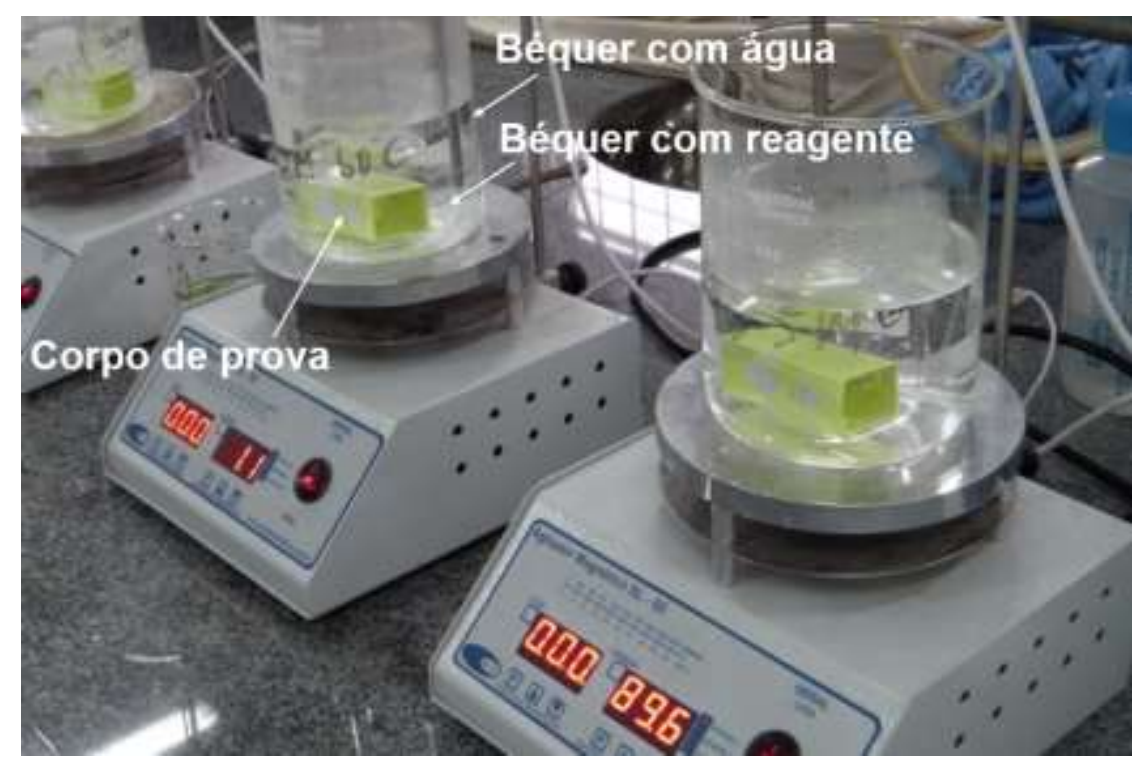

Fonte: Elaborado pelo próprio autor.

Após a usinagem, foi necessário aplicar gradualmente uma solução de ácido nítrico (HNO3) com concentração de 1 molar, para neutralizar os resíduos de base presentes. Quando a solução ficou incolor, a reação de neutralização estava concluída. Por fim, os corpos de prova foram limpos com pano seco e identificados; a Figura 11 apresenta as condições dos corpos de prova após o processo de usinagem. 
Figura 11 - Corpos de prova usinados
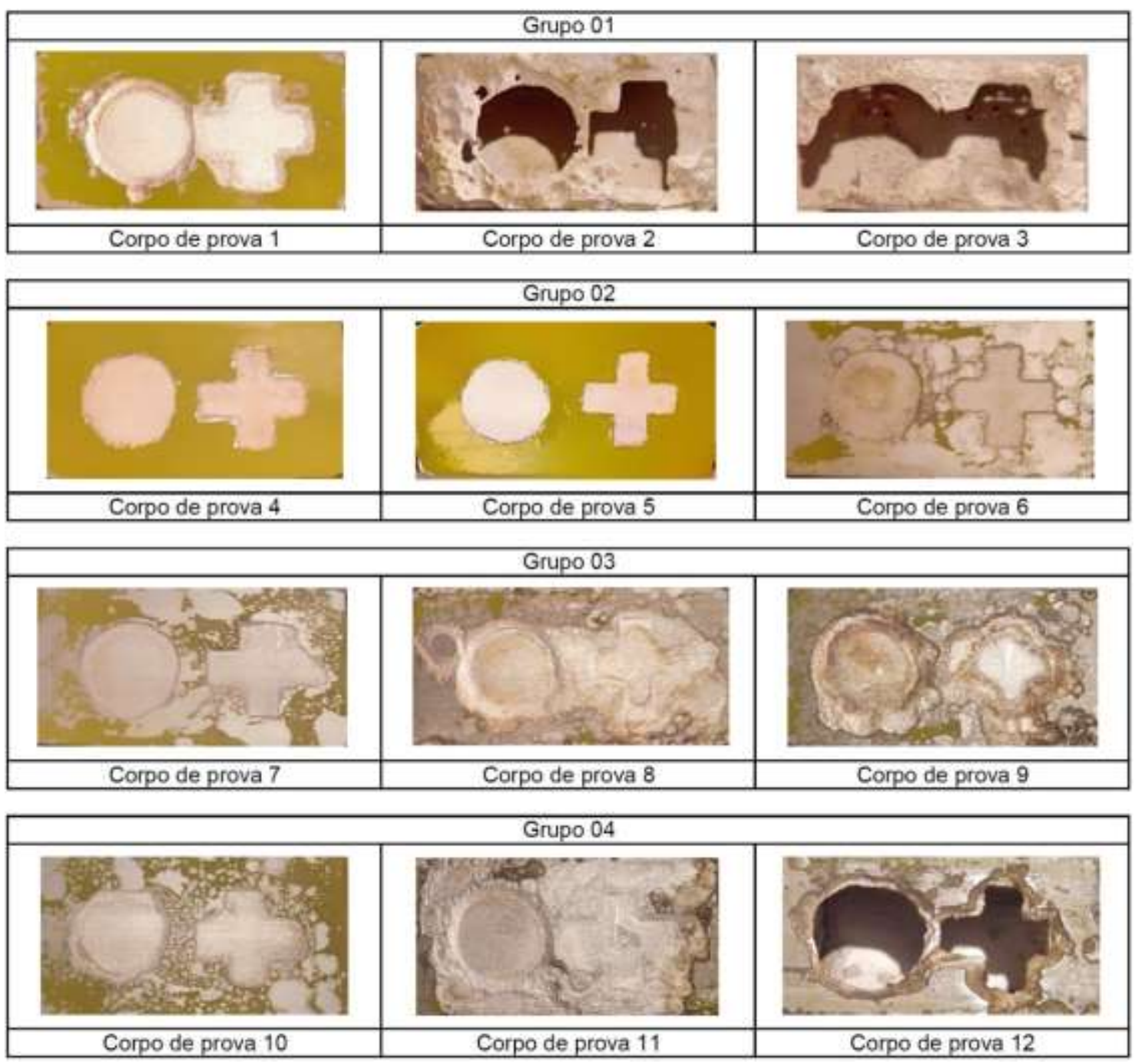

Fonte: Elaborado pelo próprio autor.

\subsection{Caracterização}

\subsubsection{Microscopia óptica}

O procedimento de microscopia óptica foi realizado com auxílio de um estereoscópio da marca Zeiss modelo Stemi 2000-C. Foram realizadas imagens com detalhes dos perfis geométricos usinados e de sua microestrutura:

A Figura 12 apresenta uma micrografia com os resultados obtidos com a usinagem química para o Grupo 01. Nesta imagem podem ser observadas uma série de erosões circulares. É necessário ressaltar que para este grupo o tempo de usinagem foi de 1h, que é a metade do tempo de reação dos demais grupos. Pode-se observar que houve desprendimento da máscara em todos os corpos de prova do Grupo 01. Os corpos de prova 2 e 3 tiveram a máscara completamente desprendida, sendo que a usinagem removeu completamente o substrato de ambos. Estes ainda apresentaram erosões circulares nos limites da forma geométrica usinada, cujo aspecto não 
foi satisfatório. A forma usinada do corpo de prova 3 deixou de ser circular, descaracterizando seu formato nominal. Isto explica-se devido à concentração de 6 molar ter sido excessiva para este material.

O corpo de prova 1 não teve o substrato completamente removido, e o desprendimento da máscara foi apenas parcial. Todavia, assim como nos corpos de prova 2 e 3 pode-se observar erosões circulares. A forma geométrica usinada manteve suas características dimensionais quando comparada com os corpos de prova 2 e 3 .

Percebe-se que uma concentração de 2,5 molar, foi menos agressiva que as outras utilizadas no Grupo 1, mas ainda apresentou-se excessiva devido às erosões circulares. O tipo de usinagem de ambas as amostras foi parcialmente anisotrópico, o que não é uma condição esperada.

Figura 12 - Micrografias do Grupo 01

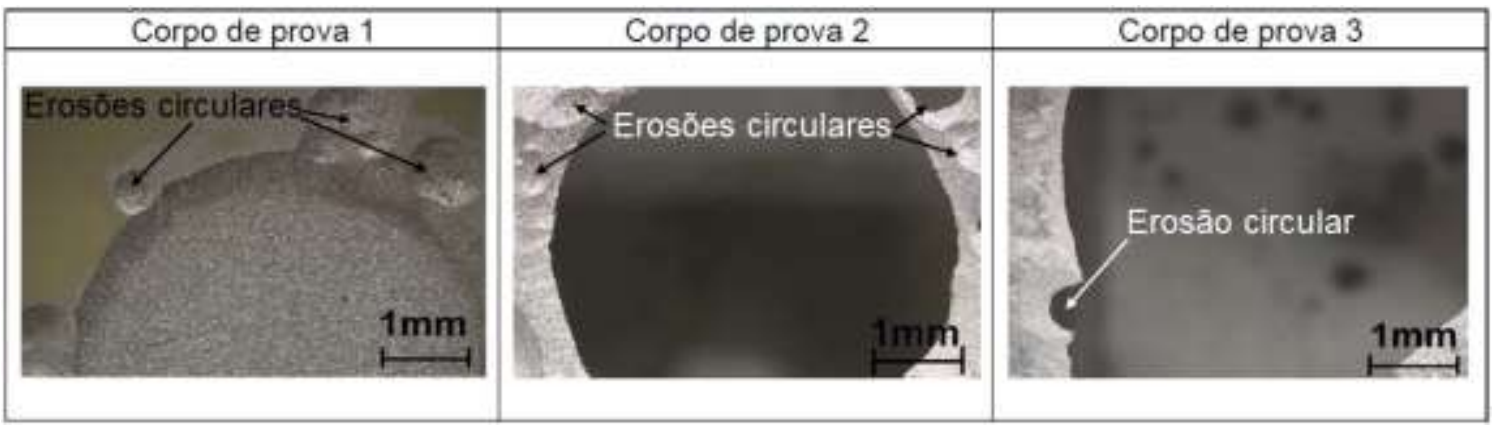

Fonte: Elaborado pelo próprio autor.

A Figura 13 apresenta as micrografias do Grupo 02. Observa-se que este foi o grupo com os resultados mais satisfatórios. Os corpos de prova 4 e 5 foram os que apresentaram melhores resultados para este grupo. Estes não apresentaram desprendimento da máscara nem erosões circulares. As formas geométricas usinadas também se apresentaram com aparência satisfatória, mantendo o perfil nominal. O tipo de usinagem para este grupo foi totalmente anisotrópica, o melhor que se pode esperar. O corpo de prova 6 apresentou desprendimento parcial da máscara e erosões circulares nos limites da forma geométrica usinada, conforme pode-se observar na Figura 13. Isto pode ser explicado devido à usinagem ter acontecido a $90^{\circ} \mathrm{C}$, a maior temperatura do grupo, que apresentou-se excessiva.

Para este grupo foi selecionada a menor concentração de reagente em relação aos demais grupos, que foi de 1,5 molar de hidróxido de sódio. A seleção deste parâmetro apresentou-se satisfatória, mantendo as características nominais do perfil usinado. 
Figura 13 - Micrografias do Grupo 02

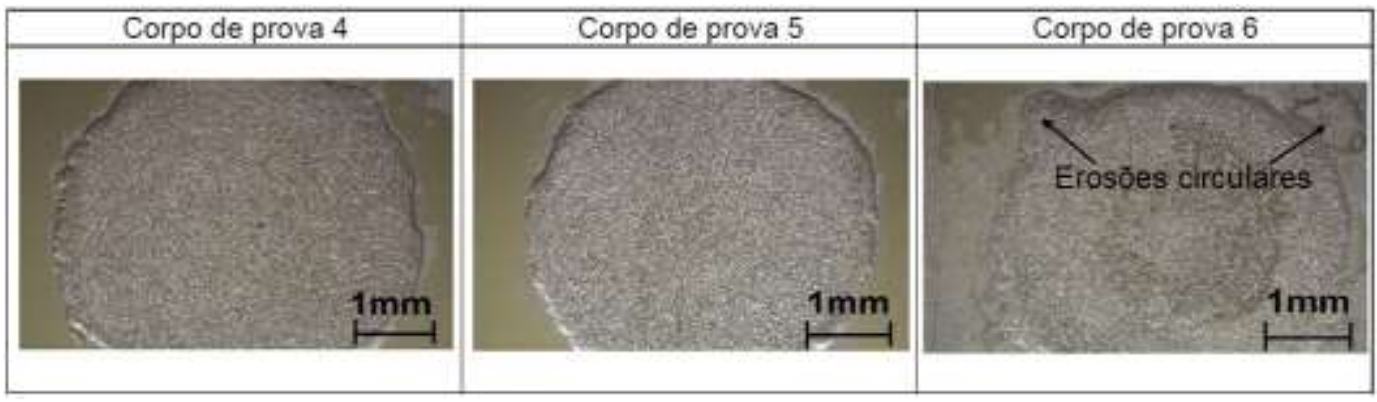

Fonte: Elaborado pelo próprio autor.

A Figura 14 apresenta as micrografias do Grupo 03. Este resultou em usinagens do tipo parcialmente anisotrópicas, com uma grande área usinada entre a máscara e o substrato. Pode-se observar que aconteceu o desprendimento parcial da máscara nos 3 corpos de prova. Os corpos de prova 8 e 9 apresentaram algumas erosões circulares, sendo que a forma geométrica usinada foi descaracterizada.

O melhor resultado para este grupo foi o corpo de prova 7 , cuja temperatura de $25^{\circ} \mathrm{C}$ foi a menor quando comparada com os demais deste grupo. Não foram constatadas erosões circulares nos limites da forma geométrica usinada.

Figura 14 - Micrografias do Grupo 03

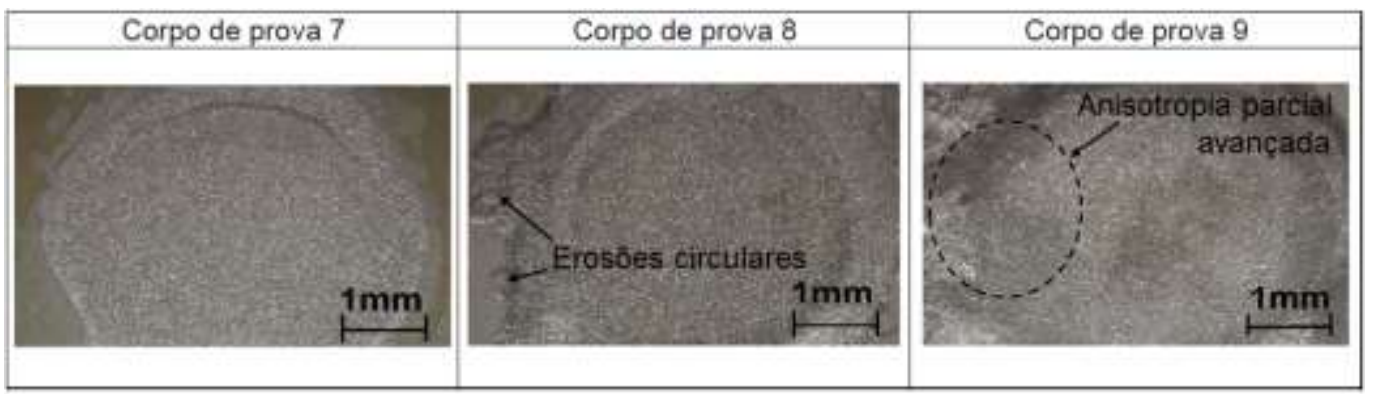

Fonte: Elaborado pelo próprio autor.

Conforme mostra a Figura 15, o Grupo 04 resultou em usinagens do tipo parcialmente anisotrópicas, com uma grande área usinada entre a máscara e o substrato, semelhante ao resultado do Grupo 03. Os corpos de prova 11 e 12 apresentaram desprendimento total da máscara e descaracterização nos limites do perfil usinado, que resultou em aparência não satisfatória. O corpo de prova 12 teve o substrato completamente removido. 
Figura 15 - Micrografias do Grupo 04

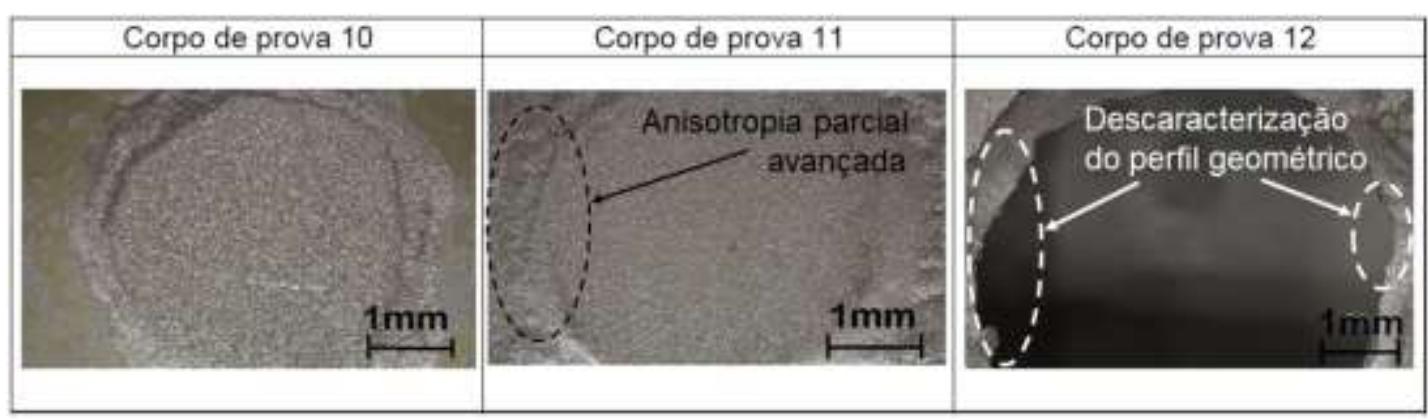

Fonte: Elaborado pelo próprio autor.

\subsubsection{Avaliação da taxa de remoção}

Conforme Çakir et al. (2008) a taxa de remoção e a profundidade da usinagem são diretamente proporcionais. Quanto maior o tempo e temperatura da reação, e maior a concentração do reagente, mais material é removido. A expressão que determina a profundidade da remoção é dada pela Equação 1.

$E=s / t$

Onde "E" é a taxa de remoção, "s" é a profundidade da usinagem e "t" é o tempo total da reação.

Os valores de taxa de remoção resultantes são apresentados na Tabela 2.

Tabela 2 - Espessura removida e taxa de remoção

\begin{tabular}{|c|c|c|c|}
\hline Identificaçăo & Grupo & Espessura removida $(\mu \mathrm{m})$ & Taxa de remoçăo ( $\mathrm{nm} / \mathrm{min}$ ) \\
\hline Corpo de prova 1 & \multirow{3}{*}{1} & 422 & 7,033 \\
\hline Corpo de prova 2 & & $>950$ & $>16$ \\
\hline Corpo de prova 3 & & $>950$ & $>16$ \\
\hline Corpo de prova 4 & \multirow{3}{*}{2} & 125 & 1,033 \\
\hline Corpo de prova 5 & & 136 & 1,133 \\
\hline Corpo de prova 6 & & 152 & 1,267 \\
\hline Corpo de prova 7 & \multirow{3}{*}{3} & 110 & 0,917 \\
\hline Corpo de prova 8 & & 410 & 3,425 \\
\hline Corpo de prova 9 & & 583 & 4,858 \\
\hline Corpo de prova 10 & \multirow{3}{*}{4} & 141 & 1,183 \\
\hline Corpo de prova 11 & & 761 & 6,342 \\
\hline Corpo de prova 12 & & $>950$ & $>8$ \\
\hline
\end{tabular}

Fonte: Elaborado pelo próprio autor.

O Grupo 01 apresentou os maiores valores tanto de espessura removida quanto da taxa de remoção. Percebe-se que nos corpos de prova 2 e 3, o valor da espessura removida foi superior à 950 $\mu$ m e da taxa de remoção superior a $16 \mathrm{~nm} / \mathrm{min}$, porque a usinagem química cortou o substrato antes do tempo de reação estipulado ser alcançado, isto se deve ao fato das concentrações de reagente selecionadas serem as mais altas quando comparadas àquelas dos demais grupos. Uma situação semelhante aconteceu com o corpo de prova 12 , 
que também teve seu substrato completamente removido pela usinagem química. Nota-se que apesar dos corpos de prova 1, 2 e 3 possuir uma concentração de reagente maior que o corpo de prova 12, um maior tempo de reação foi determinante para se atingir uma maior espessura de remoção.

Já o Grupo 02, que apresentou as melhores condições dimensionais e de acabamento, teve as menores espessuras removidas e taxas de remoção. O corpo de prova 4 resultou em espessura removida de $125 \mu m$ e uma taxa de remoção de 1,033nm/min. Isso se deve ao fato da concentração de reagente ter sido a menor neste grupo quando comparado com os demais.

Uma concentração de reagente menor que 1,5 molar, que foi utilizada no Grupo 02, tornaria o processo de usinagem química improdutivo. Isto se deve ao fato de que os valores resultantes de espessura removida e taxa de remoção seriam muito baixos.

\section{Considerações finais}

Neste trabalho, o processo de usinagem química foi desenvolvido para usinar alumínio com um reagente eficiente e de baixo custo. Através da variação de parâmetros de usinagem, obtiveram-se diferentes resultados, os quais foram analisados de maneira independente. Todavia, é a relação entre eles que apresenta qual a seleção dos parâmetros de usinagem é a mais satisfatória.

Uma seleção de parâmetros de usinagem satisfatórios não deve gerar desprendimento da máscara, nem a formação de erosões circulares. É importante que se realize um estudo da variação de parâmetros em um processo de usinagem química, pois somente assim será possível determinar quais parâmetros geram melhores resultados.

Foi constatado que havendo o desprendimento da máscara, ocorrerão erosões circulares e usinagem de áreas que não deveriam ser usinadas. Como consequência, o perfil geométrico poderá sofrer variações dimensionais em relação aos valores estipulados em projeto.

A avaliação das micrografias constatou que a seleção de parâmetros mais satisfatória é dada na seguinte condição: concentração do reagente 1,5 molar de $\mathrm{NaOH}$, temperatura da reação $60^{\circ} \mathrm{C}$ e tempo de reação $2 \mathrm{~h}$.

Pode-se observar também que a taxa de remoção é diretamente proporcional à concentração de reagente, bem como também é diretamente proporcional à temperatura. Entretanto, a seleção de parâmetros de usinagem com maiores valores pode comprometer o acabamento da peça usinada, conforme pode-se observar nos corpos de prova que foram ensaiados com alta concentração em temperatura elevada.

Foi verificado também que os resultados deste trabalho comprovam que é viável realizar a usinagem química em um tubo quadrado de alumínio através da utilização do hidróxido de sódio (NaOH) como reagente e da aplicação de uma tinta anticorrosiva como máscara, podendo-se atingir resultados satisfatórios em termos de níveis de acabamento, taxa de remoção de material e profundidade de usinagem. É importante destacar que neste trabalho não são apresentadas relações referente a custos de implantação ou compra de insumos para o processo de usinagem química. Esta avaliação é recomendada para se comparar as variáveis deste processo com outros corriqueiramente utilizados pelas indústrias.

Dentre outras oportunidades para futuros estudos, destacam-se a análise de outras variáveis que podem ser avaliadas, como a relação do posicionamento da peça durante o processo de reação química que possa ser 
mais eficiente. Ainda, pode-se avaliar se a movimentação do reagente durante a reação química provoca algum tipo de alteração, a fim de gerar melhores resultados, bem como outros tipos de máscaras que podem ser aplicadas, com o objetivo de se constatar qual pode ser mais eficiente para este processo.

Referências

Allen, D. M. (1986). The Principles and Practice of Photochemical Machining and Photoetching. IOP, UK, Adam Hilger.

ASTM D1193.

Disponível em: <https://compass-astm.ez130.periodicos.capes.gov.br/EDIT/html_annot.cgi?D1193+10>. Acessado em: 01/03/2017.

ASTM E340.

Disponível em: <https://compass-astm.ez130.periodicos.capes.gov.br/EDIT/html_annot.cgi?E340+15>. Acessado em 01/03/2017.

ASTM E407.

Disponível em: <https://compass-astm.ez130.periodicos.capes.gov.br/EDIT/html_annot.cgi?E407+07(2015)e1>. Acessado em 01/03/2017.

Bernagozzi, I. et al. (2014). Fabricating superhydrophobic aluminum: An optimized one-step wet synthesis using fluoroalkyl silane. Colloid. Surface A. 441, 919-924.

Chandler, Wayne. (2008). Pros and Cons of Alkaline vs. Acid Etching of Aluminum. Metal Finishing.

Çakir, O. et al. (2008). Chemical etching of aluminum. Journal of Materials Processing Technology. Elsevier.

Çakir, O. et al. (2005). Chemical etching of Cu-ETP copper. Journal of Materials Processing Technology. Elsevier, 275-279.

Fiorotto, N. R. (2014). Técnicas Experimentais em Química: Normas e Procedimentos. 1ạ. Ed. São Paulo: editora Erica.

Furtado, P. (2009). Pintura Anticorrosiva dos Metais. RJ: editora LTC.

Huang et al. (2015). Superhydrophobic aluminum alloy surfaces prepared by chemical etching process and their corrosion reistance properties. Applied Surface Science. Elsevier.

Lakatos, E. M.; Marconi, M. A. (2011). Metodologia científica. 6. ed. São Paulo: Atlas.

Liao, R. et al. (2014). Fabrication of superhydrophobic surface on aluminum by continuous chemical etching and its anti-icing property. Appl. Surf. Sci, 317, 701-709.

Nayak, A. P. et al. (2009). Wet and Dry Etching. Disponível em: <http://web.ece.ucdavis.edu/ anayakpr/Papers/Wet\%20and\%20Dry\%20Etching_submitted.pdf >. Article. University of California, California. Acessado em 01/03/2019.

Ruan, M. et al. (2012). Optimal conditions for the preparation of superhydrophobic surfaces on al substrates using a simple etching approach. Appl. Surf. Sci, 258, 7031-7035.

Saleema, N. et al. (2011). Chemical Nature of Superhydrophobic Aluminum Alloy Surfaces Produced via a OneStep Process Using Fluoroalkyl-Silane in a Base Medium. ACS Appl. Mater. \& Interfaces, 3, 4775-4781. 
Tarasova, V. A. (1968). Chemical Milling (Deep Contour Etching). Defense Technical Information Center.

Torng et al. (2009). Process Control for Aerospace Chemical Milling Process. International Journal of Manufacturing Technology and Management. Inderscience.

Walker, Perrin. Tarn, William H. (1991). Handbook of Metal Etchants. CRC Press.

Recebido em: 23 maio 2018 / Aprovado em: 18 fev. 2019

Para referenciar este texto

Moura, C. R., \& Scaburi, A. G. (2020). Avaliação dos parâmetros do processo de usinagem química com $\mathrm{NaOH}$ em tubos quadrados de alumínio. Exacta, 18(2) 293-310. https://doi.org/10.5585/ExactaEP.v18n2.8709. 